\title{
Syntheses and Polymerizations of Novel Chiral Methacrylates Bearing Urethane Bonds and $N$, $N$-Dibenzylamino Groups
}

\author{
Yong-Kyung LEE, Kenjiro ONIMURA, Hiromori TsUTSUMI, and Tsutomu OISHI ${ }^{\dagger}$ \\ Department of Applied Chemistry and Chemical Engineering, Faculty of Engineering, \\ Yamaguchi University, 2-16-1 Tokiwadai, Ube, Yamaguchi, 755-8611 Japan
}

(Received June 14, 2000; Accepted September 1, 2000)

\begin{abstract}
Four new chiral methacrylates bearing urethane bonds and $N$, $N$-dibenzylamino groups (RMOC) were synthesized from 2-methacryloyloxyethyl isocyanate (MOI) and four chiral alcohol derivatives of $\alpha$-amino acids, Lvaline, L-leucine, D-phenylglycine, and L-phenylalanine. Radical polymerizations of RMOC were performed under various conditions to obtain the corresponding poly(RMOC) with number average molecular weights $\left(\bar{M}_{\mathrm{n}}\right)$ of $2.4 \times 10^{4}-6.4 \times$ $10^{4}$. Poly(RMOC) has hydrogen bonds based on urethane segments in solvent and exhibited negative (levo) rotation. Specific optical rotations of poly(RMOC) were slightly influenced by solvent and temperature. Radical copolymerizations of RMOC with styrene (ST) and methyl methacrylate (MMA) were performed with AIBN in toluene at $60^{\circ} \mathrm{C}$. Monomer reactivity ratios $\left(r_{1}, r_{2}\right)$ and Alfrey-Price $Q \cdot e$ were determined. Chiroptical properties of the copolymers were scarcely affected by $c o$-units of ST and MMA. Chiral stationary phases (CSPs) for high performance liquid chromatography (HPLC) were prepared from poly(RMOC) and silica gel and optical resolution ability was investigated. CSPs resolved some racemic compounds $(\mathbf{1}-\mathbf{5})$ using methanol/water as mobile phase.

KEY WORDS 2-Methacryloyloxyethyl Isocyanate / Radical Polymerization / Copolymerization / Monomer Reactivity Ratios / Chiral Stationary Phase / High Performance Liquid Chromatography /
\end{abstract}

2-Methacryloyloxyethyl isocyanate (MOI) is a difunctional monomer with a reactive isocyanate group and polymerizable double bond. ${ }^{1}$ Many MOI derivatives have been synthesized from several alcohols and amines, and polymerized. ${ }^{2}$ MOI is useful for preparation of macromonomer. ${ }^{3}$ However there have been few reports on the synthesis of MOI derivatives bearing optically active

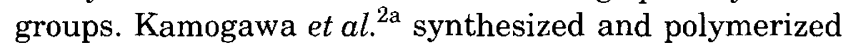
$l$-menthyl $N$-(2-methacryloyloxyethyl)carbamate (MnM OC) and investigated the utilization of hydrolytic properties of various bonds between the monomer and polymer. Bamford et al. ${ }^{4}$ synthesized MOI derivatives from $\alpha$-amino acid and D-glucosamine and examined applications of polymers to blood compatibility. To our knowledge, no chiroptical properties of MOI derivatives with optically active groups have been reported. Thus, the authors lately investigated polymerizations and chiroptical properties of cholesteryl $N$-(2-methacryloyloxyethyl)carbamate (ChMOC) and MnMOC. ${ }^{5}$

A wide variety of chiral stationary phases (CSPs) has recently been developed for the separation of enantiomers by high performance liquid chromatography (HPLC). ${ }^{6}$ Although many synthetic chiral polymers were applied to $\operatorname{CSPs}^{7}$ there have been few reports on the preparation of CSPs for HPLC from polymethacrylate bearing a chiral pendant group in spite of their availability. Only Miyano et $a l^{8}{ }^{8}$ synthesized optically active polymethacrylates each bearing a 1,1'-binaphthalene moiety as pendant group and investigated on optical resolution ability as chiral adsorbent for HPLC. The reason may the low chiral recognition ability of the chiral pendant group and/or the absence of the stable higher-ordered structure of the polymers. ${ }^{7}$ However, methacrylamides bearing a chiral pendant groups served as CSPs with highly recognition ability. Blaschke et al. ${ }^{9}$ and Arlt et $a l .{ }^{10}$ reported the synthesis of many chiral methacrylamides from $\alpha$-amino acids and their chiral recognition ability.

This article describes the synthesis of four new chiral methacrylate (RMOC) with urethane bonds and $\alpha$ amino acids derivatives, and radical homopolymerizations, copolymerizations, and chiroptical properties of the polymers obtained. CSPs were prepared by chemical reaction of silica gel and poly(RMOC). Optical resolution ability of the CSPs was investigated by HPLC.

\section{EXPERIMENTAL}

\section{Materials}

Styrene (ST) and methyl methacrylate (MMA) were purified by ordinary methods. ${ }^{11}$ Tetrahydrofuran (THF), benzene, and toluene were dried over sodium metal and used after distillation. $N, N$-Dimethylformamide (DMF), dichloromethane, and chloroform were used after distillation. 2,2'Azobisisobutyronitrile (AIBN) was purified by recrystallization from methanol. Other reagents were used without further purification. Monomers of RMOC were synthesized, as drawn in Scheme 1.

Amino Alcohols. Four amino alcohols, $(S)$-valinol, $(S)$-leucinol, $(R)$-phenylglycinol, and $(S)$-phenylalaninol, were synthesized from L-valine, L-leucine, D-phenylglycine, and L-phenylalanine, respectively, by the ordinary methods. ${ }^{12}$

(S) and (R)-2-(N, N-Dibenzylamino)-substituted-1-ol (DBR). (S)-2-( $N, N$-Dibenzylamino)-3-methylbutane-1-ol (DBM B), $(S)$-2-( $N, N$-dibenzylamino)-4-methylpentane-1-ol (DB $\mathrm{MP}),(R)-2-(N, N$-dibenzylamino)-2-phenylethane-1-ol (D $\mathrm{BPhE}$ ), and (S)-2-( $N, N$-dibenzylamino)-3-phenylpropane-1-ol $(\mathrm{DBPhP})$ were synthesized from $(S)$-valinol, $(S)$ leucinol, $(R)$-phenylglycinol, and $(S)$-phenylalaninol, re-

\footnotetext{
${ }^{\dagger}$ To whom all correspondence should be addressed (Tel\&Fax:+81-836-85-9281, E-mail: oishi@po.cc.yamaguchi-u.ac.jp).
} 

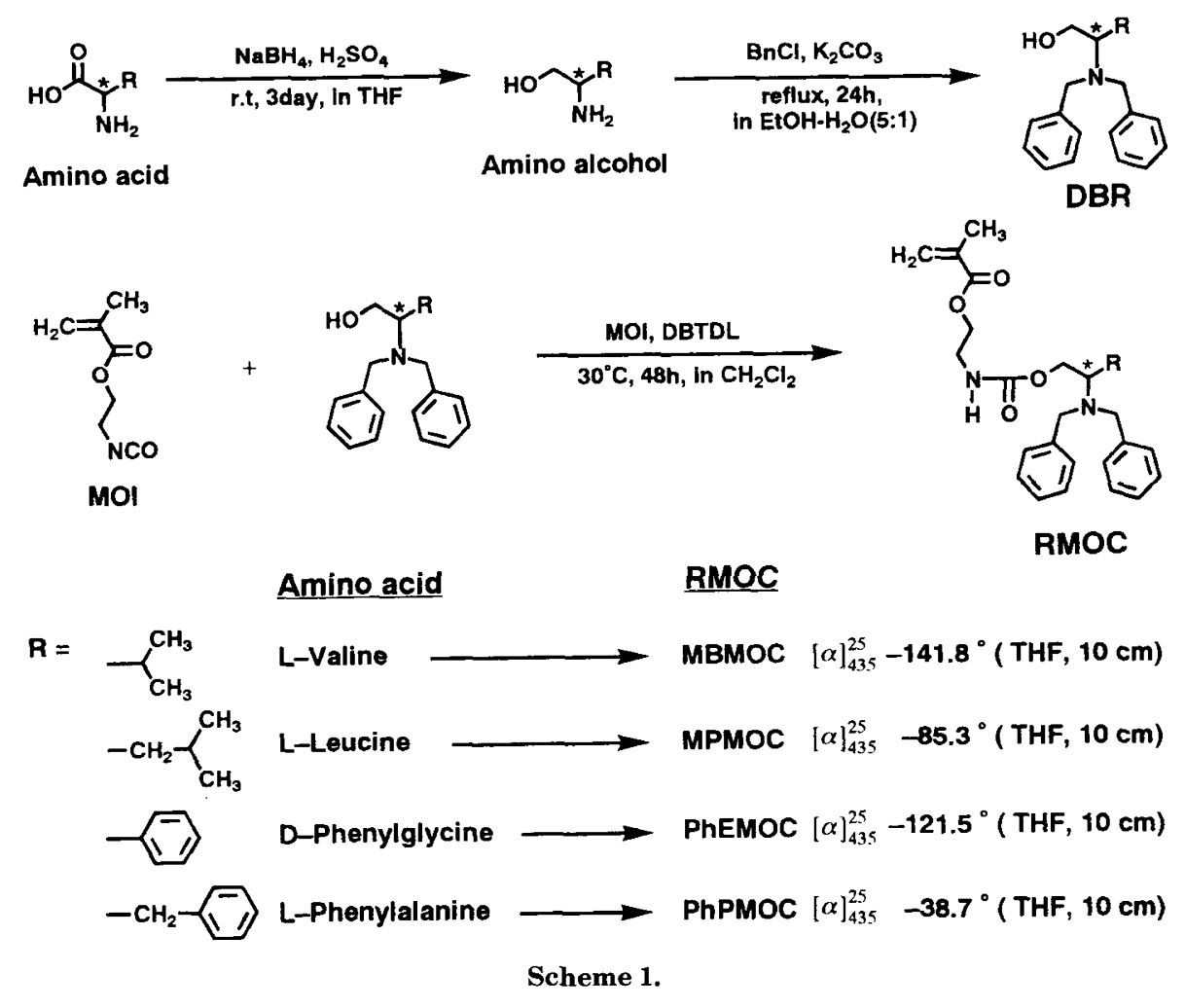

spectively, by ordinary methods. ${ }^{13}$

(S)-(2-(N, N-Dibenzylamino)-3-methyl)butyl N-(2-methacryloyloxyethyl) carbamate (MBMOC). A solution of MOI $\left(1.97 \mathrm{~g}, 1.27 \times 10^{-2} \mathrm{~mol}\right)$ was added dropwise to a stirred solution of DBMB $\left(3.01 \mathrm{~g}, 1.06 \times 10^{-2} \mathrm{~mol}\right)$ and di- $n$-butyltin dilaurate (DBTDL) $\left(0.01 \mathrm{~g}, 1.58 \times 10^{-5}\right.$ mol) in $\mathrm{CH}_{2} \mathrm{Cl}_{2}(30 \mathrm{~mL})$ under nitrogen at r.t. The solution was heated at $35^{\circ} \mathrm{C}$ and stirred for $48 \mathrm{~h}$ under nitrogen. The reaction mixture was extracted with distilled water. The organic layer was dried with anhydrous magnesium sulfate, filtered, and evaporated under reduced pressure to give the crude product. Purification by chromatography on silica gel with $n$-hexane / ethyl acetate (4 /1) as eluent gave MBMOC as a pale yellow viscous oil: yield $67.1 \%$; $[\alpha]_{435}^{25}-141.8^{\circ}\left(c=1.0 \mathrm{~g} \mathrm{dL}^{-1}, l=10 \mathrm{~cm}, \mathrm{TH}\right.$ $\mathrm{F}) ;{ }^{1} \mathrm{H}$ NMR ( $\delta$, ppm from TMS in $\mathrm{CDCl}_{3}$ ) 7.37-7.18 (m, $10 \mathrm{H}$, in phenyl groups), $6.13\left(\mathrm{~s}, 1 \mathrm{H}\right.$, (trans) $\mathrm{CH}_{2}=\mathrm{C}$ ), 5.59 (s, $1 \mathrm{H}$, (cis) $\mathrm{CH}_{2}=\mathrm{C}$ ), 4.95 (bs, $\left.1 \mathrm{H}, \mathrm{N}-\mathrm{H}\right), 4.44-4.39$ (dd, $2 \mathrm{H}, J=3.68$ and $8.25,2 \times \mathrm{PhCH}_{\mathrm{A}} \mathrm{H}_{\mathrm{B}} \mathrm{N}$ ), $4.29-4.25$ $\left(\mathrm{t}, 2 \mathrm{H}, J=5.28, \mathrm{COOCH}_{2}\right), 3.90-3.85(\mathrm{~d}, 2 \mathrm{H}, J=3.85,2$ $\left.\times \mathrm{PhCH}_{\mathrm{A}} \mathrm{H}_{\mathrm{B}} \mathrm{N}\right), 3.56-3.48\left(\mathrm{~m}, 4 \mathrm{H}, \mathrm{CH}_{2} \mathrm{NHCOOCH}_{2}\right)$, $2.45-2.38(\mathrm{~m}, 1 \mathrm{H}, \mathrm{CH}-\mathrm{N}), 1.95\left(\mathrm{bs}, 4 \mathrm{H}, \mathrm{CH}\left(\mathrm{CH}_{3}\right)_{2}\right.$ and $\left.\mathrm{CH}_{2}=\mathrm{C}\left(\mathrm{CH}_{3}\right)\right), 1.03-0.84\left(\mathrm{dd}, 6 \mathrm{H}, \mathrm{J}=6.60, \mathrm{CH}\left(\mathrm{CH}_{3}\right)_{2}\right)$; ${ }^{13} \mathrm{C} \mathrm{NMR}$ ( $\delta$, ppm from TMS in $\left.\mathrm{CDCl}_{3}\right) 167.76(\mathrm{C}=\mathrm{O})$, $156.84(\mathrm{~N}-\mathrm{C}=\mathrm{O}), 140.61,129.36,128.57,127.22$ (in phenyl groups), $136.41(=\mathrm{C}<), 126.52\left(\mathrm{CH}_{2}=\right), 64.10$ $\left(\mathrm{NHCOOCH}_{2}\right), 63.00\left(\mathrm{COOCH}_{2}\right), 62.50(\mathrm{~N}-\mathrm{CH}), 55.01$ $\left(\mathrm{PhCH}_{2} \mathrm{~N}\right), \quad 40.72 \quad\left(\mathrm{CH}_{2} \mathrm{NHCOO}\right), 28.38 \quad\left(\mathrm{CH}\left(\mathrm{CH}_{3}\right)_{2}\right)$, 21.58, $20.70\left(\mathrm{CH}\left(\mathrm{CH}_{3}\right)_{2}\right), 18.76\left(\mathrm{CH}_{2}=\mathrm{C}\left(\mathrm{CH}_{3}\right)\right)$.

(S)-(2- $N, N$-Dibenzylamino)-4-methyl)pentyl $N$-(2-methacryloyloxyethyl) carbamate (MPMOC), $(R)-\left(2,2^{\prime}-(N\right.$, $N$-Dibenzylamino)phenyl)ethyl $N$-(2-methacryloyloxyethyl)carbamate (PhEMOC), and $(S)-(2-(N, N$-Dibenzylamino)-3-phenyl)propyl $N$-(2-methacryloyloxyethyl)carbamate (PhPMOC) were synthesized from DBMP,
$\mathrm{DBPhE}$, and $\mathrm{DBPhP}$, respectively, by the same procedure as for MBMOC.

MPMOC. Yield $64.7 \%[\alpha]_{435}^{25}-85.3^{\circ}\left(c=1.0 \mathrm{~g} \mathrm{dL}^{-1}, l\right.$ $=10 \mathrm{~cm}, \mathrm{THF}) ;{ }^{1} \mathrm{H}$ NMR $\left(\delta\right.$, ppm from TMS in $\left.\mathrm{CDCl}_{3}\right)$ $7.36-7.16(\mathrm{~m}, 10 \mathrm{H}$, in phenyl groups), $6.12(\mathrm{~s}, 1 \mathrm{H}$, (trans) $\mathrm{CH}_{2}=\mathrm{C}$ ), 5.57 (s, $1 \mathrm{H}$, (cis) $\mathrm{CH}_{2}=\mathrm{C}$ ), 5.11 (bs, $1 \mathrm{H}$, $\mathrm{N}-\mathrm{H}), 4.48-4.05\left(\mathrm{~m}, 4 \mathrm{H}, 2 \times \mathrm{PhCH}_{\mathrm{A}} \mathrm{H}_{\mathrm{B}} \mathrm{N}\right.$ and $\left.\mathrm{COOCH}_{2}\right)$, $3.73-3.52\left(\mathrm{~m}, \quad 6 \mathrm{H}, \quad 2 \times \mathrm{PhCH}_{\mathrm{A}} \mathrm{H}_{\mathrm{B}} \mathrm{N}\right.$ and $\mathrm{CH}_{2}$ $\left.\mathrm{NHCOOCH}_{2}\right), 3.50-3.45(\mathrm{~m}, 1 \mathrm{H}, \mathrm{CH}-\mathrm{N}), 1.93(\mathrm{~s}, 3 \mathrm{H}$, $\left.\mathrm{CH}_{3}\right), 1.78-1.42\left(\mathrm{dm}, 1 \mathrm{H}, \mathrm{CH}_{\mathrm{A}} \mathrm{H}_{\mathrm{B}} \mathrm{CH}\left(\mathrm{CH}_{3}\right)_{2}\right), 1.26-1.20$ $\left(\mathrm{m}, 1 \mathrm{H}, \mathrm{CH}_{\mathrm{A}} \mathrm{H}_{\mathrm{B}} \mathrm{CH}\left(\mathrm{CH}_{3}\right)_{2}\right), 1.15-0.77\left(\mathrm{dm}, 1 \mathrm{H}, \mathrm{CH}_{\mathrm{A}} H_{\mathrm{B}}\right.$ $\left.\mathrm{CH}\left(\mathrm{CH}_{3}\right)_{2}\right), 0.84-0.61$ (dd, $6 \mathrm{H}, J=6.60, \mathrm{CH}_{\mathrm{A}} \mathrm{H}_{\mathrm{B}} \mathrm{CH}$ $\left.\left(\mathrm{CH}_{3}\right)_{2}\right) ;{ }^{13} \mathrm{C} \mathrm{NMR}$ ( $\delta$, ppm from TMS in $\left.\mathrm{CDCl}_{3}\right) 167.22(\mathrm{C}$ $=\mathrm{O}), 156.41(\mathrm{~N}-\mathrm{C}=\mathrm{O}), 140.2,128.82,128.25,126.74$ (in phenyl groups), $135.90(=\mathrm{C}<), 125.97\left(\mathrm{CH}_{2}=\right), 64.96$ $\left(\mathrm{NHCOOCH}_{2}\right), 63.61\left(\mathrm{COOCH}_{2}\right), 53.95(\mathrm{~N}-\mathrm{CH}), 53.82$ $\left(\mathrm{PhCH}_{2} \mathrm{~N}\right), 40.18\left(\mathrm{CH}_{2} \mathrm{NHCOO}\right), 37.65\left(\mathrm{CH}_{2} \mathrm{CH}\left(\mathrm{CH}_{3}\right)_{2}\right)$, $24.85\left(\mathrm{CH}_{2} \mathrm{CH}\left(\mathrm{CH}_{3}\right)_{2}\right), 23.24,22.23\left(\mathrm{CH}_{2} \mathrm{CH}\left(\mathrm{CH}_{3}\right)_{2}\right)$, $18.24\left(\mathrm{CH}_{3}\right)$.

PhEMOC. Yield 98.7\%; $[\alpha]_{435}^{25}-121.5^{\circ}(c=1.0 \mathrm{~g}$ $\mathrm{dL}^{-1}, l=10 \mathrm{~cm}$, THF); ${ }^{1} \mathrm{H}$ NMR ( $\delta$, ppm from TMS in $\left.\mathrm{CDCl}_{3}\right) 7.42-7.19(\mathrm{~m}, 15 \mathrm{H}$, in phenyl groups), $6.10(\mathrm{~s}, 1$ $\mathrm{H}$, (trans) $\mathrm{CH}_{2}=\mathrm{C}$ ), 5.58 (s, $1 \mathrm{H},($ cis $) \mathrm{CH}_{2}=\mathrm{C}$ ), 4.89 (bs, 1 $\mathrm{H}, \mathrm{N}-\mathrm{H}$ ), $4.73-4.66$ (dd, $1 \mathrm{H}, J=4.29$ and 6.93 , $\mathrm{PhCH}_{\mathrm{A}} \mathrm{H}_{\mathrm{B}} \mathrm{N}$ ), 4.50-4.43 (dd, $1 \mathrm{H}, J=3.63$ and 7.25 , $\mathrm{PhCH}_{\mathrm{A}} \mathrm{H}_{\mathrm{B}} \mathrm{N}$ ), 4.24-4.20 (t, $\left.2 \mathrm{H}, J=5.28, \mathrm{COOCH}_{2}\right), 4.07$ $-4.02(\mathrm{t}, 1 \mathrm{H}, J=6.92, \mathrm{CH}-\mathrm{N}), 3.82-3.77(\mathrm{~d}, 2 \mathrm{H}, J=$ $\left.3.86,2 \times \mathrm{PhCH}_{\mathrm{A}} \mathrm{H}_{\mathrm{B}} \mathrm{N}\right), 3.49-3.47\left(\mathrm{~d}, 2 \mathrm{H}, J=4.62, \mathrm{CH}_{2}\right.$ $\mathrm{NHCOO}$ ), 3.36-3.31 (d, 2H, $J=3.53$, $\mathrm{NHCOOCH}_{2}$ ), 1.93 (s, $\left.3 \mathrm{H}, \mathrm{CH}_{3}\right) ;{ }^{13} \mathrm{C} \mathrm{NMR}$ ( $\delta$, ppm from TMS in $\mathrm{CDCl}_{3}$ ) $167.24(\mathrm{C}=\mathrm{O}), 156.26(\mathrm{~N}-\mathrm{C}=\mathrm{O}), 139.75,129.06,128.75$, $128.70,128.23,128.18,127.48,126.92$ (in phenyl groups), $135.92(=\mathrm{C}<), 126.04\left(\mathrm{CH}_{2}=\right), 63.63\left(\mathrm{COOCH}_{2}\right.$ and $\left.\mathrm{NHCOOCH}_{2}\right), 60.40(\mathrm{~N}-\mathrm{CH}), 54.05\left(\mathrm{PhCH}_{2} \mathrm{~N}\right), 40.16$ $\left(\mathrm{CH}_{2} \mathrm{NHCOO}\right), 18.28\left(\mathrm{CH}_{3}\right)$. 


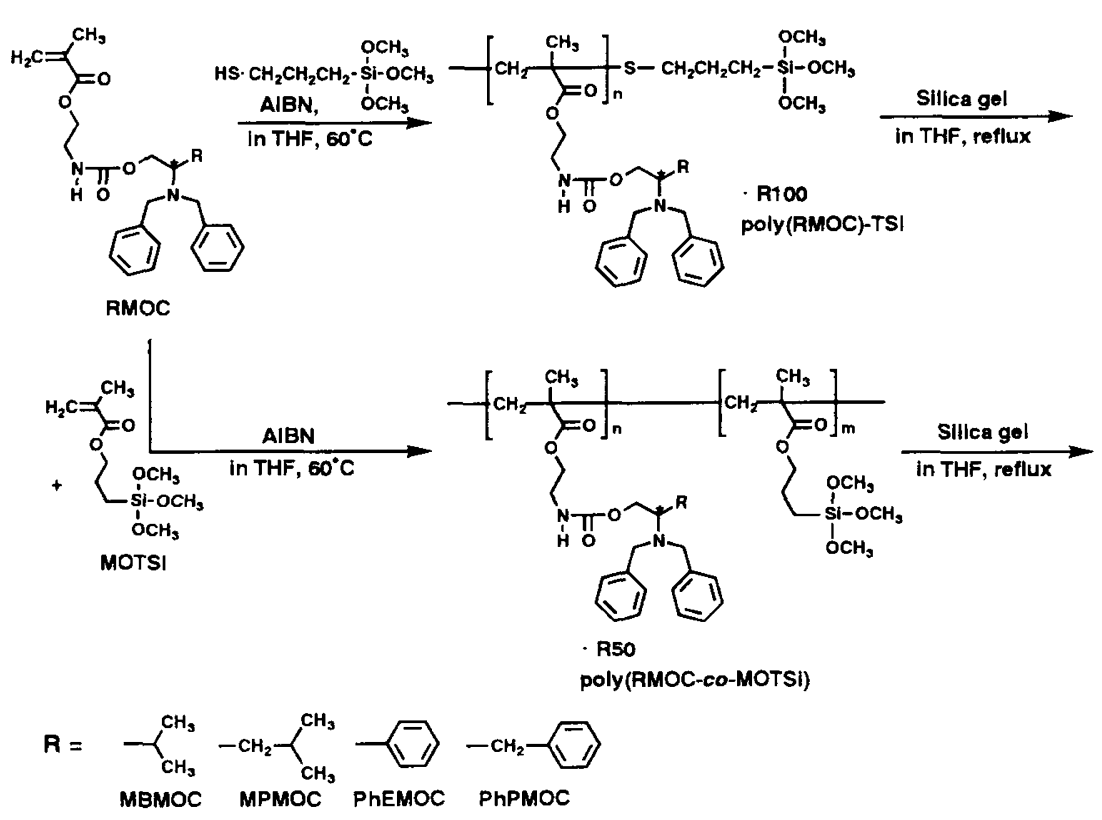

MBMOC MPMOC PhEMOC PhPMOC
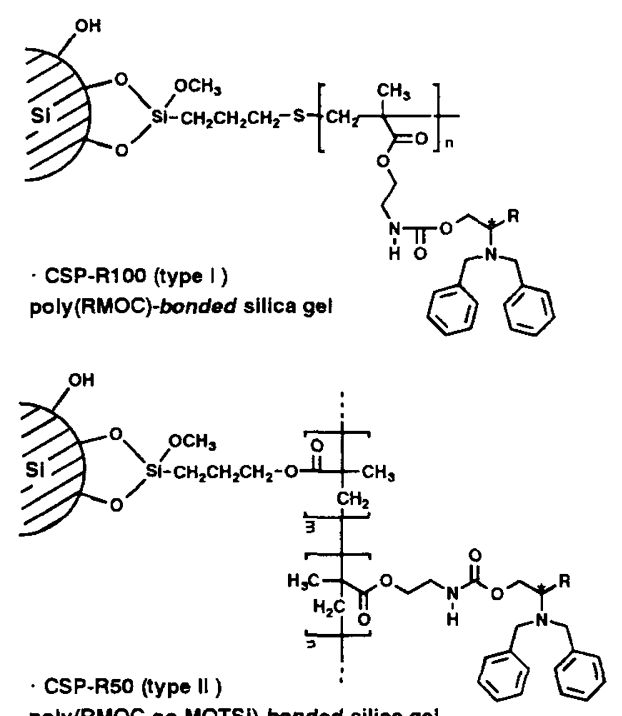

poly(RMOC-co-MOTSI)-bonded silica gel<smiles>CCCCCCCCCCCCC</smiles>

Packing materials

Scheme 2.

PhPMOC. Yield 63.0\%; $[\alpha]_{435}^{25}-38.7^{\circ}\left(c=1.0 \mathrm{~g} \mathrm{dL}^{-1}\right.$, $l=10 \mathrm{~cm}, \mathrm{THF}) ;{ }^{1} \mathrm{H} \mathrm{NMR}\left(\delta, \mathrm{ppm}\right.$ from TMS in $\mathrm{CDCl}_{3}$ ) $7.23-7.03(\mathrm{~m}, 15 \mathrm{H}$, in phenyl groups), $6.12(\mathrm{~s}, 1 \mathrm{H}$, (trans) $\left.\mathrm{CH}_{2}=\mathrm{C}\right), 5.57\left(\mathrm{~s}, 1 \mathrm{H},(\right.$ cis $\left.) \mathrm{CH}_{2}=\mathrm{C}\right), 4.95(\mathrm{bs}, 1 \mathrm{H}$, $\mathrm{N}-\mathrm{H}), 4.33-4.07\left(\mathrm{~m}, 4 \mathrm{H}, 2 \times \mathrm{PhCH}_{\mathrm{A}} \mathrm{H}_{\mathrm{B}} \mathrm{N}\right.$ and $\left.\mathrm{COOCH}_{2}\right)$, $3.72\left(\mathrm{bs}, 4 \mathrm{H}, 2 \times \mathrm{PhCH}_{\mathrm{A}} \mathrm{H}_{\mathrm{B}} \mathrm{N}\right.$ and $\left.\mathrm{NHCOOCH}_{2}\right), 3.51-$ 3.45 (d, $\left.2 \mathrm{H}, J=5.28, \mathrm{CH}_{2} \mathrm{NHCOO}\right), 3.20-3.16(\mathrm{~m}, 1 \mathrm{H}$, $\mathrm{CH}-\mathrm{N}$ ), $3.00-2.92$ (dd, $1 \mathrm{H}, \quad J=6.60$ and 6.93, $\mathrm{PhCH}_{\mathrm{A}} \mathrm{H}_{\mathrm{B}}$ ), 2.72-2.64 (dd, $1 \mathrm{H}, J=5.94$ and 7.59, $\left.\mathrm{PhCH}_{\mathrm{A}} \mathrm{H}_{\mathrm{B}}\right), 1.93\left(\mathrm{~s}, 3 \mathrm{H}, \mathrm{CH}_{3}\right) ;{ }^{13} \mathrm{C} \mathrm{NMR}(\delta, \mathrm{ppm}$ from TMS in $\left.\mathrm{CDCl}_{3}\right)$ 167.21 $(\mathrm{C}=\mathrm{O}), 156.24(\mathrm{~N}-\mathrm{C}=\mathrm{O}), 139.77$, $139.46,129.20$, 128.91, 128.54, 128.46, 128.19, 128.05, $126.15,125.98$ (in phenyl groups), $135.89(=\mathrm{C}<), 125.95$ $\left(\mathrm{CH}_{2}=\right), 64.19\left(\mathrm{NHCOOCH}_{2}\right), 63.58\left(\mathrm{COOCH}_{2}\right), 58.26(\mathrm{~N}$ $-\mathrm{CH}), \quad 53.17\left(\mathrm{PhCH}_{2} \mathrm{~N}\right), \quad 40.15 \quad\left(\mathrm{CH}_{2} \mathrm{NHCOO}\right), 34.34$ $\left(\mathrm{PhCH}_{2}\right), 18.22\left(\mathrm{CH}_{3}\right)$.

\section{Radical Polymerization}

Radical homopolymerization and copolymerization were performed with AIBN as initiator in a suitable solvent in a sealed tube at $60^{\circ} \mathrm{C}$. After polymerization, the polymer solution was poured into excess methanol to precipitate the polymer. The resulting polymer was purified by reprecipitating it twice from THF solution into excess methanol. The supernatant was decanted and the polymer dried in vacuo for 3 days. The compositions of copolymers were found from ${ }^{1} \mathrm{H}$ NMR spectra and elemental analysis $(\mathrm{N})$.

\section{Preparation of Packing Materials and Column Packing}

As shown in Scheme 2, poly(RMOC)s with terminal trimethoxysilane groups (poly(RMOC)-TSi, R100) and poly(RMOC-co-methacryloyloxypropyl trimethoxy silane (MOTSi)) (R50) were synthesized by radical homopolymerization using 3-mercaptopropyl trimethoxysilane as chain-transfer agent and copolymerization with MOTSi, respectively. The chiral polymer (R100 or R50, $0.5 \mathrm{~g}$ ) was dissolved in THF (15 mL), and silica gel (TOSOH, TSKGEL SI 100: mean particle size, $5 \mu \mathrm{m}$; pore size $100 \AA$ ) $(1.0 \mathrm{~g})$ was added to the solution. The solution was refluxed for $24 \mathrm{~h}$ under nitrogen and cooled to r.t. The solvent was removed by filtration and the polymer-bonded silica gel was washed with THF and methanol and then dried in vacuo for 1 day. RMOC segment content on the silica gel obtained was estimated from IR spectra. Chiral packing materials was packed in a stainless steel HPLC column (i.d., $0.2 \mathrm{~cm}$; length, $10 \mathrm{~cm}$ ) by a slurry method. Plate numbers of columns were measured for toluene in methanol as eluent at a flow rate of $0.5 \mathrm{~mL} \mathrm{~min}^{-1}$ at ambient temperature.

\section{Measurements}

NMR spectra were recorded at $25^{\circ} \mathrm{C}$ using JEOL EX270 (JEOL Ltd.). IR spectra were recorded on Shimadzu FT-IR-8100 A (Shimadzu Ltd.). Elemental analysis was carried out with a $\mathrm{CHN}$ recorder (Yanagimoto Co.). Gel permeation chromatography (GPC) measurements were carried out at $50^{\circ} \mathrm{C}$ using THF as eluent on a Shimadzu SPD-10 A (Shimadzu Ltd.) equipped with a UV detector, HSG-40, HSG-20, HSG-15, and HSG-10 columns and Jasco OR 990 (Japan Spectroscopic Co.) with a polarimetric detector. Specific optical rotations were measured with a Jasco DIP-140 (5 and $10 \mathrm{~cm}$ quartz cell lengths, $c=1.0 \mathrm{~g} \mathrm{dL}^{-1}$ in THF). HPLC measurements were carried out on a Shimadzu LC-10AT with UV detection at $254 \mathrm{~nm}$.

\section{RESULTS AND DISCUSSION}

\section{Radical homopolymerizations of RMOC}

Radical polymerizations of RMOC were performed with AIBN as initiator at $60^{\circ} \mathrm{C}$ in various solvents. The results are summarized in Table I. All polymerizations proceeded homogeneously throughout. The obtained 
Table I. Radical homopolymerization of RMOC with AIBN in several solvents $(2 \mathrm{~mL})$ for $24 \mathrm{~h}$ at $60^{\circ} \mathrm{C}^{a}$

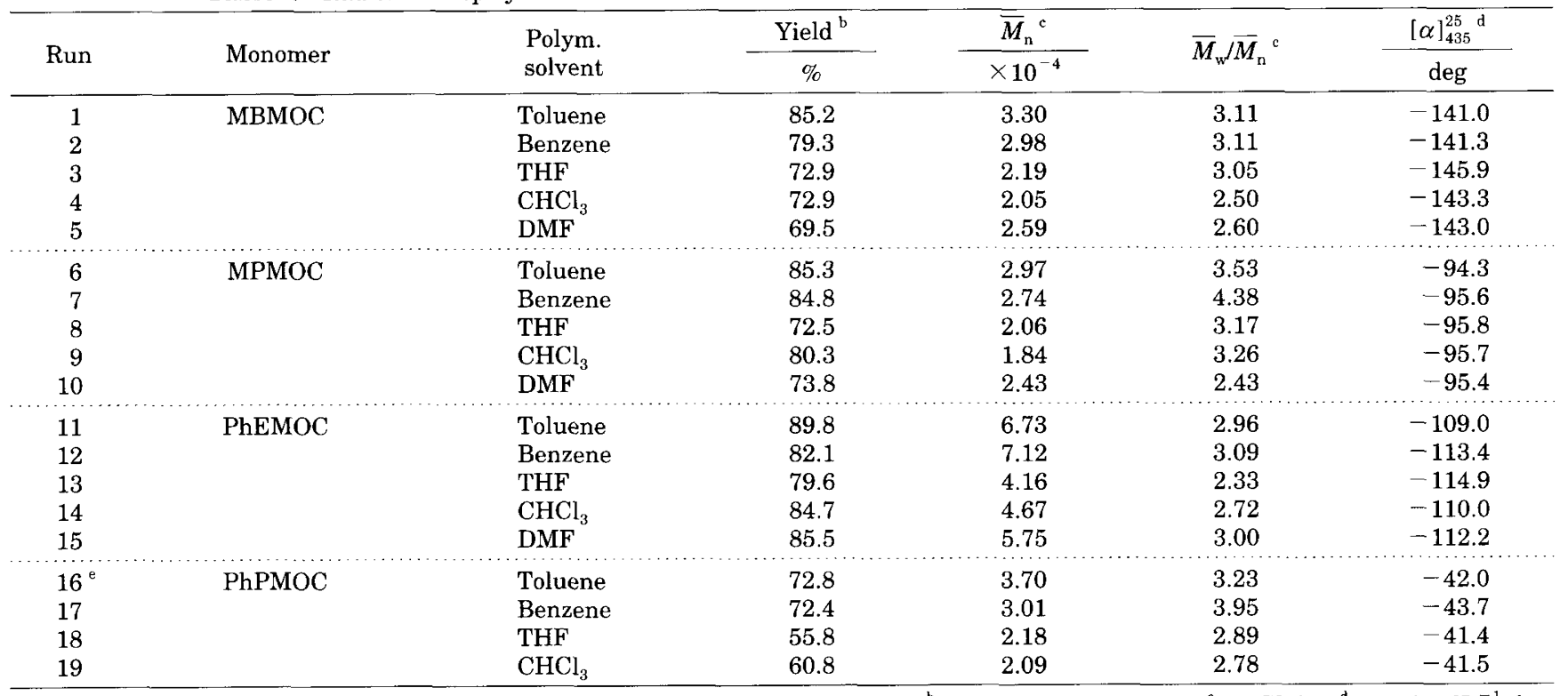

${ }^{\mathrm{a}}$ Monomer $=0.5 \mathrm{~g}$; AIBN, 2,2 -azobisisobutyronitrile; [AIBN]/[Monomer] $=0.03 .{ }^{\mathrm{b}} \mathrm{MeOH}$-insoluble part. ${ }^{\mathrm{c}} \mathrm{By} \mathrm{GPC} .^{\mathrm{d}} c=1.0 \mathrm{~g} \mathrm{dL}{ }^{-1}, l=$ $10 \mathrm{~cm}, \mathrm{THF}$. ${ }^{\mathrm{e}}$ Monomer $=1.0 \mathrm{~g} ;$ toluene $=5 \mathrm{~mL} ;[\mathrm{AIBN}] /[$ Monomer $]=0.08$.

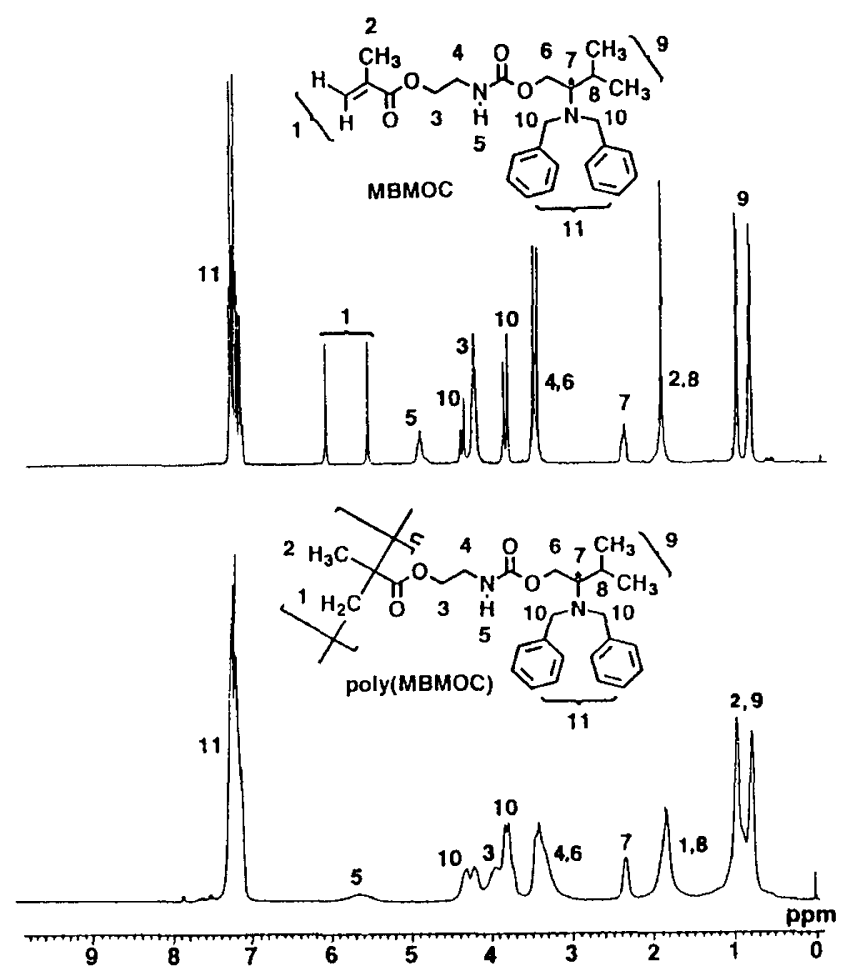

Figure 1. ${ }^{1} \mathrm{H}$ NMR spectra for MBMOC and poly(MBMOC) in $\mathrm{CDCl}_{3}$ at $23.5^{\circ} \mathrm{C}(270 \mathrm{MHz})$.

polymers were colorless or pale yellow powders, though sticky and rubbery in methanol and $n$-hexane. The resulting polymers were soluble in organic solvents such as THF, chloroform, and benzene. Poly(RMOC) showed counterdextro specific optical rotations $\left(\left[\alpha_{435}^{25}\right]\right)$ of -41.4 $-145.9^{\circ}$. Chiroptical properties of the polymers will be described later. Figure 1 shows ${ }^{1} \mathrm{H}$ NMR spectra of MBMOC and poly(MBMOC). Peaks at $6.13 \mathrm{ppm}$ and $5.59 \mathrm{ppm}$ assigned to vinyl $\left(\mathrm{CH}_{2}=\mathrm{C}<\right)$ groups disappeared and those due to carbamate (-NHCOO-) groups

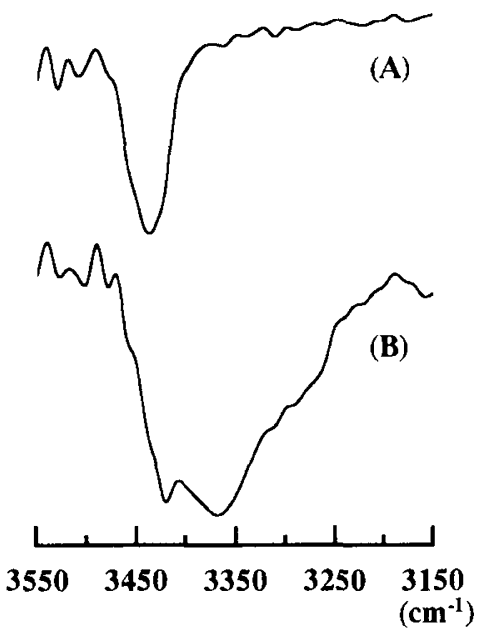

Figure 2. Infrared spectra for (A) PhPMOC and (B) poly(PhPMOC) in benzene; $c=1.0 \mathrm{~g} \mathrm{dL}^{-1}$.

at $4.95 \mathrm{ppm}$ became broad and shifted to $5.70 \mathrm{ppm}$ after polymerization, suggesting that ordinary vinyl radical polymerization completely proceeded. Expanded IR spectra of PhPMOC and poly(PhPMOC) measured in benzene are shown in Figure 2. A sharp absorption peak due to stretching vibration of $\mathrm{N}-\mathrm{H}$ for PhPMOC appeared at $3440 \mathrm{~cm}^{-1}$. For poly $(\mathrm{PhPMOC})$, the peak shifted from $3440 \mathrm{~cm}^{-1}$ to $3365 \mathrm{~cm}^{-1}$ and became broad, suggesting that the polymers had hydrogen bonds based on urethane segments. For other poly(RMOC)s, similar results were observed. Figure 3 shows ${ }^{1} \mathrm{H}$ NMR spectra of poly(MBMOC) measured at various temperatures and concentrations. With increasing temperature, the broad peak due to carbamate groups at $5.70 \mathrm{ppm}$ shifted slightly to the high magnetic field, as well as the peak due to methylene groups adjacent to the carbamate groups at $3.42 \mathrm{ppm}$. However, such chemical shift was not observed by changing concentration. The polymer 


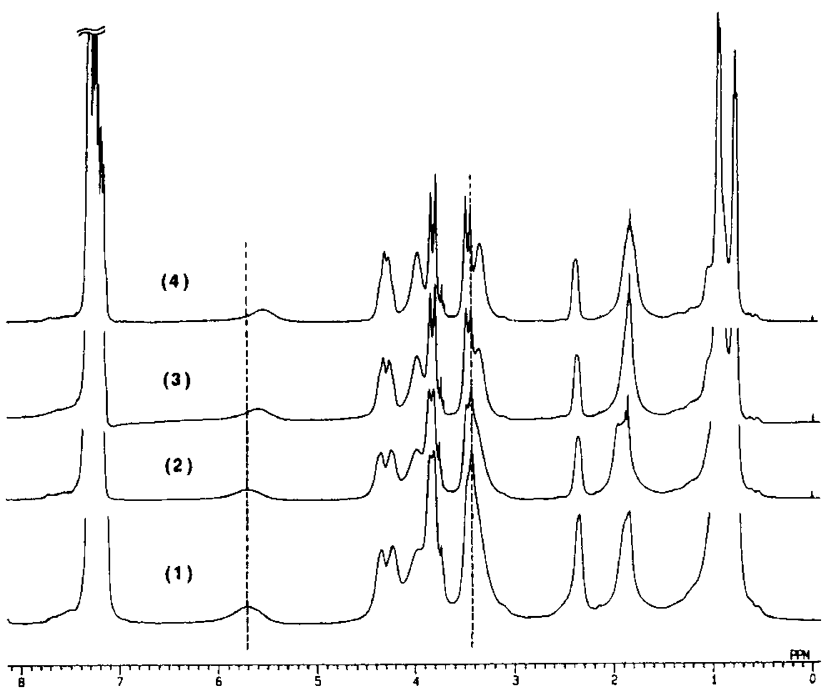

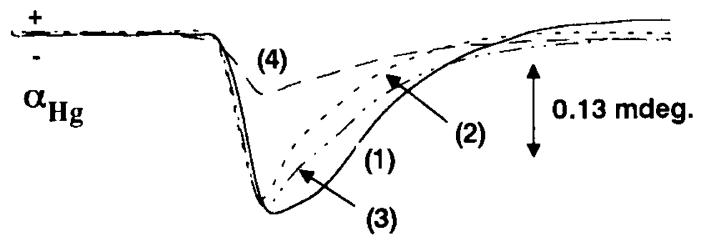

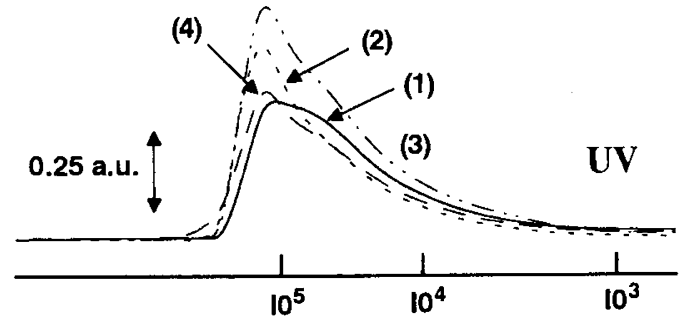

Figure 4. GPC curves of poly(RMOC): (1) run 3, (2) run 7, (3) run 13 , and (4) run 16 in Table I.

Figure 3. ${ }^{1} \mathrm{H}$ NMR spectra for MBMOC and poly(MBMOC) in $\mathrm{CDCl}_{3}$ at $(1) 23.2^{\circ} \mathrm{C}\left(c=2.0 \mathrm{~g} \mathrm{dL}^{-1}\right),(2) 23.2^{\circ} \mathrm{C}\left(c=0.75 \mathrm{~g} \mathrm{dL}^{-1}\right),(3)$ $40^{\circ} \mathrm{C}\left(c=0.75 \mathrm{~g} \mathrm{dL}^{-1}\right)$, and $50^{\circ} \mathrm{C}\left(c=0.75 \mathrm{~g} \mathrm{dL}^{-1}\right)$.

Table II. Radical Copolymerizations of RMOC $\left(M_{1}\right)$ with ST $\left(M_{2}\right)$ in Toluene $(2 \mathrm{~mL})$ at $60^{\circ} \mathrm{C}^{\text {a }}$

\begin{tabular}{|c|c|c|c|c|c|c|c|c|c|c|}
\hline \multirow[t]{2}{*}{ Run } & \multirow{2}{*}{$\mathrm{M}_{1}$} & \multirow[t]{2}{*}{$\mathrm{M}_{2}$} & \multirow{2}{*}{$\frac{\begin{array}{c}\mathrm{M}_{1} \text { in } \\
\text { monomer feed }\end{array}}{\text { mol\% }}$} & \multirow{2}{*}{$\frac{\begin{array}{c}\text { Polym. } \\
\text { time }\end{array}}{\mathrm{h}}$} & \multirow{2}{*}{$\frac{\text { Yield }^{b}}{\%}$} & \multicolumn{2}{|c|}{$\begin{array}{l}\mathrm{M}_{1} \text { in } \\
\text { copolymer }^{\mathrm{c}}\end{array}$} & \multirow{2}{*}{$\frac{\bar{M}_{\mathrm{n}}{ }^{\mathrm{d}}}{\times 10^{-4}}$} & \multirow[t]{2}{*}{$\bar{M}_{\mathrm{w}} \bar{M}_{\mathrm{n}}^{\mathrm{b}}$} & \multirow{2}{*}{$\frac{[\alpha]_{435}^{25} \mathrm{e}}{\operatorname{deg}}$} \\
\hline & & & & & & $\mathrm{mol} \%$ & $\mathrm{wt} \%$ & & & \\
\hline 1 & MBMOC & $\mathrm{ST}$ & 9.8 & 12.0 & 33.4 & 20.1 & 51.4 & 1.30 & 1.68 & -63.2 \\
\hline 2 & & $\mathrm{ST}$ & 19.9 & 11.0 & 34.6 & 31.5 & 66.0 & 1.44 & 1.71 & -91.1 \\
\hline 3 & & ST & 30.0 & 8.0 & 18.1 & 44.6 & 77.2 & 1.92 & 1.73 & $-105.4^{f}$ \\
\hline 4 & & ST & 48.8 & 7.0 & 26.3 & 61.7 & 87.1 & 2.14 & 1.88 & -120.9 \\
\hline 5 & & ST & 69.7 & 4.0 & 12.0 & 69.3 & 90.5 & 3.27 & 2.03 & $-132.4^{\mathrm{g}}$ \\
\hline 6 & & ST & 79.5 & 2.5 & 20.2 & 83.7 & 95.6 & 3.55 & 2.17 & $-136.9^{\mathrm{h}}$ \\
\hline 7 & MPMOC & ST & 10.2 & 9.0 & 13.8 & 14.4 & 42.3 & 1.37 & 1.67 & $-41.5^{\mathrm{i}}$ \\
\hline 8 & & ST & 20.3 & 9.0 & 24.3 & 23.5 & 57.2 & 1.72 & 1.73 & -58.1 \\
\hline 9 & & ST & 30.2 & 6.0 & 8.5 & 31.1 & 66.3 & 2.01 & 1.76 & $-67.6^{\mathrm{g}}$ \\
\hline 10 & & ST & 50.1 & 5.5 & 22.8 & 67.5 & 90.0 & 2.28 & 2.00 & $-82.2^{\mathrm{h}}$ \\
\hline 11 & & $\mathrm{ST}$ & 79.1 & 3.5 & 21.3 & 70.9 & 91.0 & 3.48 & 2.10 & -86.5 \\
\hline 12 & PhEMOC & $\mathrm{ST}$ & 9.1 & 5.5 & 7.3 & 18.8 & 51.2 & 1.51 & 1.86 & $-50.0^{\mathrm{j}}$ \\
\hline 13 & & ST & 20.8 & 5.5 & 5.0 & 35.6 & 71.5 & 1.80 & 1.80 & $-72.2^{\mathrm{k}}$ \\
\hline 14 & & $\mathrm{ST}$ & 24.3 & 5.0 & 6.6 & 38.1 & 73.6 & 1.78 & 1.89 & $-76.8^{j}$ \\
\hline 15 & & $\mathrm{ST}$ & 47.5 & 4.5 & 6.2 & 62.8 & 88.5 & 2.28 & 2.12 & $-89.5^{j}$ \\
\hline 16 & & $\mathrm{ST}$ & 68.5 & 4.0 & 10.0 & 75.6 & 93.4 & 2.39 & 2.13 & $-96.6^{\mathrm{l}}$ \\
\hline 17 & & $\mathrm{ST}$ & 81.6 & 3.5 & 18.2 & 88.9 & 97.3 & 3.00 & 2.30 & $-101.2^{\mathrm{m}}$ \\
\hline 18 & PhPMOC & ST & 10.5 & 9.5 & 14.7 & 21.1 & 55.6 & 1.27 & 1.86 & $-22.5^{\mathrm{m}}$ \\
\hline 19 & & ST & 20.9 & 9.5 & 20.7 & 33.1 & 69.8 & 1.38 & 2.05 & $-29.4^{\mathrm{m}}$ \\
\hline 20 & & ST & 30.1 & 9.5 & 29.3 & 40.2 & 75.9 & 1.62 & 2.37 & -31.8 \\
\hline 21 & & $\mathrm{ST}$ & 48.2 & 7.0 & 11.4 & 58.6 & 86.9 & $-^{\mathrm{n}}$ & $-^{n}$ & $-^{\mathrm{n}}$ \\
\hline 22 & & ST & 69.5 & 5.0 & 15.4 & 66.4 & 90.2 & 2.54 & 3.75 & $-38.5^{\mathrm{m}}$ \\
\hline 23 & & ST & 79.5 & 3.5 & 10.5 & 88.0 & 97.2 & 3.58 & 3.69 & $-38.5^{\mathrm{m}}$ \\
\hline
\end{tabular}

${ }^{\mathrm{a}} \mathrm{M}_{1}+\mathrm{M}_{2}=0.5 \mathrm{~g}$; initiator, 2,2'-azobisisobutyronitrile $\left(0.03 \mathrm{~mol} \mathrm{~L}^{-1}\right)$. ${ }^{\mathrm{b}}$ Methanol insoluble part. ${ }^{\mathrm{c}}$ By elemental analysis. ${ }^{\mathrm{d}}$ By GPC with polystyrene standard. ${ }^{\mathrm{e}} c=1.0 \mathrm{~g} \mathrm{dL}^{-1}, l=10 \mathrm{~cm}$, THF. ${ }^{\mathrm{f}} c=0.7 \mathrm{~g} \mathrm{dL}^{-1}, l=10 \mathrm{~cm}$, THF. ${ }^{\mathrm{g}} c=0.4 \mathrm{~g} \mathrm{dL}^{-1}, l=10 \mathrm{~cm}$, THF. ${ }^{\mathrm{h}} c=0.8 \mathrm{~g}$ $\mathrm{dL}^{-1}, l=10 \mathrm{~cm}$, THF. ${ }_{\mathrm{i}} c=0.5 \mathrm{~g} \mathrm{dL}^{-1}, l=10 \mathrm{~cm}, \mathrm{THF} .{ }^{\mathrm{j}} c=0.4 \mathrm{~g} \mathrm{dL}^{-1}, l=5 \mathrm{~cm}, \mathrm{THF} .{ }^{\mathrm{k}} c=0.36 \mathrm{~g} \mathrm{dL}^{-1}, l=5 \mathrm{~cm}, \mathrm{THF} .{ }^{1} c=0.8 \mathrm{~g} \mathrm{dL}{ }^{-1}, l=$ $5 \mathrm{~cm}$, THF. ${ }^{\mathrm{m}} c=1.0 \mathrm{~g} \mathrm{dL}^{-1}, l=5 \mathrm{~cm}$, THF. ${ }^{\mathrm{n}}$ Not determined.

may thus have intra- rather than intermolecular hydrogen bonds based on urethane segments.

Figure 4 depicts GPC curves of poly(RMOC)s. Number-average molecular weights $\left(\bar{M}_{\mathrm{n}}\right)$ of poly(RMOC)s were $1.84 \times 10^{4}-7.12 \times 10^{4}$, and slightly affected by polymerization solvents. $\bar{M}_{\mathrm{n}}$ of poly(PhEMOC) was larger than those of other polymers. Polydispersities (weight average molecular weight $\left(\bar{M}_{\mathrm{w}} / \bar{M}_{\mathrm{n}}\right)$ for poly(RMOC)s were $2.33-4.38$ and relatively large. Yields of poly(RMOC)s were $55.8-89.8 \%$ and influenced only by polymerization solvents.
Radical copolymerizations of RMOC with ST and MMA

The results of radical copolymerizations of $\operatorname{RMOC}\left(\mathrm{M}_{1}\right)$ with ST $\left(\mathrm{M}_{2}\right)$ or MMA $\left(\mathrm{M}_{2}\right)$ using AIBN in toluene at 60 ${ }^{\circ} \mathrm{C}$ are summarized in Tables II and III. All copolymerizations proceeded homogeneously throughout. The copolymers were colorless or pale yellow powders and optically active. $\bar{M}_{\mathrm{n}}$ s of poly(RMOC-co-ST)s and poly(RMOCco-MMA)s were $1.27 \times 10^{4}-3.58 \times 10^{4}$ and $2.51 \times 10^{4}$ $7.45 \times 10^{4}$, respectively. $\bar{M}_{\mathrm{n}} \mathrm{s}$ of all copolymers increased with the content of $\mathrm{M}_{1}$ in the copolymer. $\left(\bar{M}_{\mathrm{w}} / \bar{M}_{\mathrm{n}}\right) \mathrm{s}$ for the copolymers were $1.67-6.74$ and comparatively 
Table III. Radical Copolymerizations of RMOC $\left(\mathrm{M}_{1}\right)$ with MMA $\left(\mathrm{M}_{2}\right)$ in Toluene $(2 \mathrm{~mL})$ at $60^{\circ} \mathrm{C}^{a}$

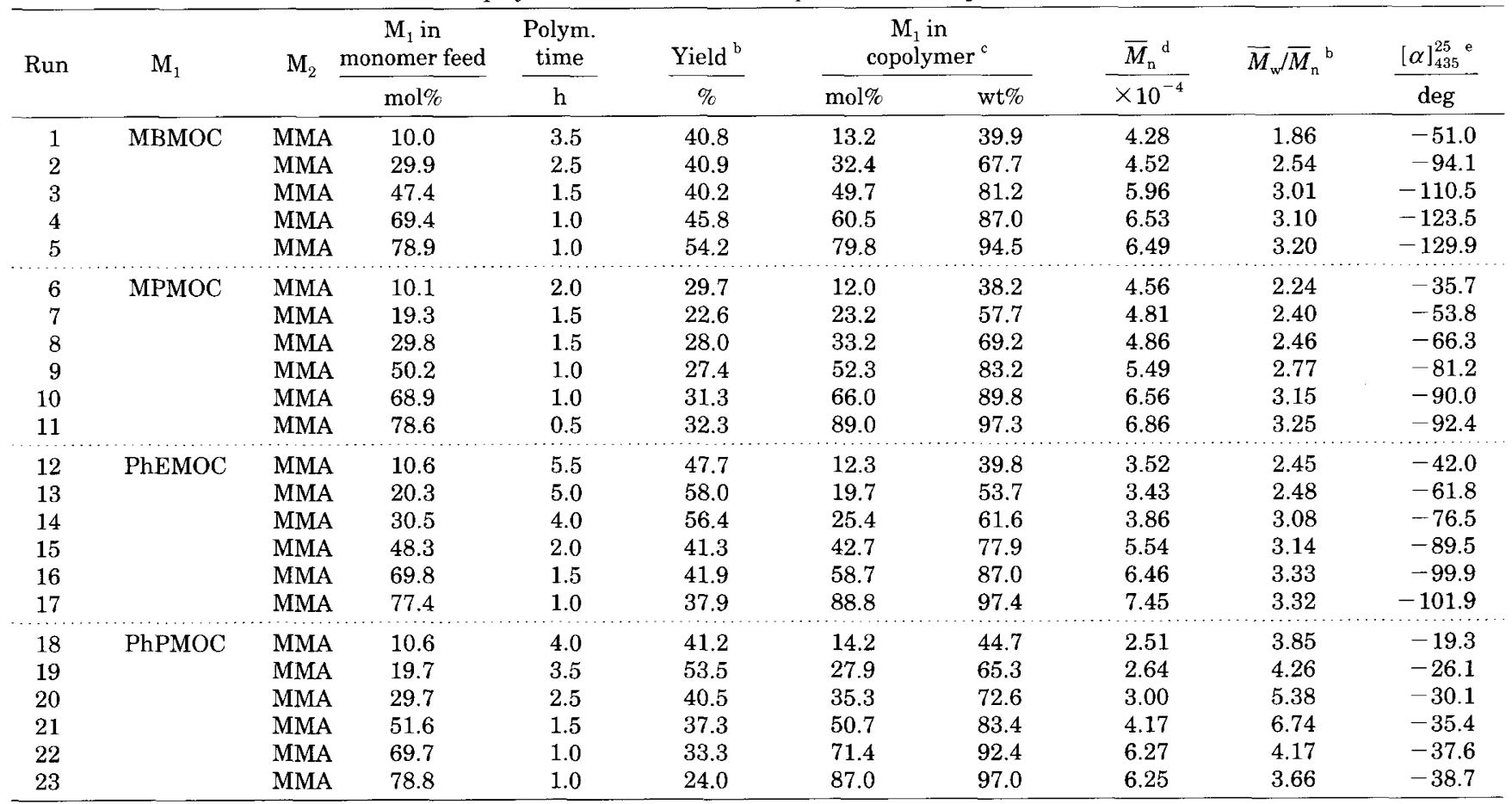

${ }^{a} \mathrm{M}_{1}+\mathrm{M}_{2}=0.5 \mathrm{~g}$; initiator, 2,2'-azobisisobutyronitrile $\left(0.03 \mathrm{~mol} \mathrm{~L}^{-1}\right),{ }^{\mathrm{b}}$ Methanol insoluble part. ${ }^{\mathrm{c}}$ By elemental analysis. ${ }^{\mathrm{d}}$ By GPC with polystyrene standard. ${ }^{\mathrm{e}} \mathrm{c}=1.0 \mathrm{~g} \mathrm{dL}-1, l=10 \mathrm{~cm}$, THF.

Table IV. Monomer Reactivity Ratios $\left(r_{1}, r_{2}\right)$ and Alfrey-Price $Q-e$ values

\begin{tabular}{|c|c|c|c|c|c|c|}
\hline $\mathrm{M}_{1}$ & $\mathbf{M}_{2}$ & $r_{1}$ & $r_{2}$ & $Q_{1}$ & $e_{1}$ & Reference \\
\hline MBMOC & ST & 0.99 & 0.30 & 1.39 & 0.30 & this work \\
\hline MPMOC & $\mathrm{ST}$ & 0.52 & 0.48 & 0.81 & 0.38 & this work \\
\hline PhEMOC & ST & 1.33 & 0.38 & 1.37 & 0.03 & this work \\
\hline PhPMOC & $\mathrm{ST}$ & 1.14 & 0.38 & 1.27 & 0.12 & this work \\
\hline ChMOC & $\mathrm{ST}$ & 0.38 & 0.42 & 0.80 & 0.55 & 5 \\
\hline MnMOC & $\mathrm{ST}$ & 0.41 & 0.52 & 0.72 & 0.45 & 5 \\
\hline MBMOC & MMA & 0.64 & 0.61 & 1.80 & 1.37 & this work \\
\hline PhEMOC & MMA & 0.69 & 0.74 & 1.38 & 1.22 & this work \\
\hline PhPMOC & MMA & 1.15 & 0.56 & 1.74 & 1.07 & this work \\
\hline ChMOC & MMA & 0.99 & 0.83 & 1.07 & 0.84 & 5 \\
\hline MnMOC & MMA & 0.45 & 0.73 & 1.54 & 1.45 & 5 \\
\hline
\end{tabular}

large.

Copolymer composition curves in the polymerizations of RMOC with ST or MMA are shown in Figure 5. Table IV gives monomer reactivity ratios $\left(r_{1}, r_{2}\right)$ obtained by the high-conversion method reported by Tüdös et al. ${ }^{14}$ and Alfrey-Price $Q-e^{15}$ for RMOC. Figure 4 and Table IV show that copolymerization systems of RMOC with ST or MMA have similar reactivities. $Q_{1}$ and $e_{1}$ in the RMOC-ST system were different from those in the RMOC-MMA system. In the Alfrey-Price $Q$ and $e$ theory, no steric effect is taken into account. RMOCs may have possibly relatively high steric hindrance because of a large $N, N$-dibenzylamino group. These copolymerization parameters were similar to those for other RMOC copolymers. ${ }^{5}$

Chiroptical Properties of Homopolymers and Copolymers

Poly(RMOC)s exhibited negative (levo) specific optical rotations as well as the corresponding monomers. In Figure 4, GPC curves for poly(RMOC)s taken with a po- larimetric detector also show negative peaks, whose patterns were in accord with the corresponding UV curves. Thus chiroptical properties of poly(RMOC)s were not affected by $\bar{M}_{\mathrm{n}}$. Specific optical rotations of the polymers were scarcely influenced by polymerization solvents (Table I), but the values changed according to measurement solvents, and were in the range of $-140.6^{\circ}-145.9^{\circ}$ for poly(MBMOC), $-87.3^{\circ}-101.7^{\circ}$ for poly(MPMOC), $106.4^{\circ}--123.7^{\circ}$ for poly(PhEMOC), and $-42.0^{\circ}--$ $56.5^{\circ}$ for poly(PhPMOC), as shown in Figure 6A. Specific optical rotations of poly $(\mathrm{RMOC}) \mathrm{s}$ measured at various temperatures in benzene are shown in Figure 6B. The absolute values of the specific optical rotations of poly (RMOC)s increased almost linearly with decrease in temperature, and these changes were reversible due in part to change in conformation caused by hydrogen bonds between urethane branches.

Figure 7 shows relationships between specific optical rotations and content ( $\mathrm{wt} \%$ ) of monomeric unit of RMOC in poly $\left(\mathrm{RMOC}-\mathrm{co}-\mathrm{M}_{2}\right) \mathrm{s}$. Absolute specific optical rota- 


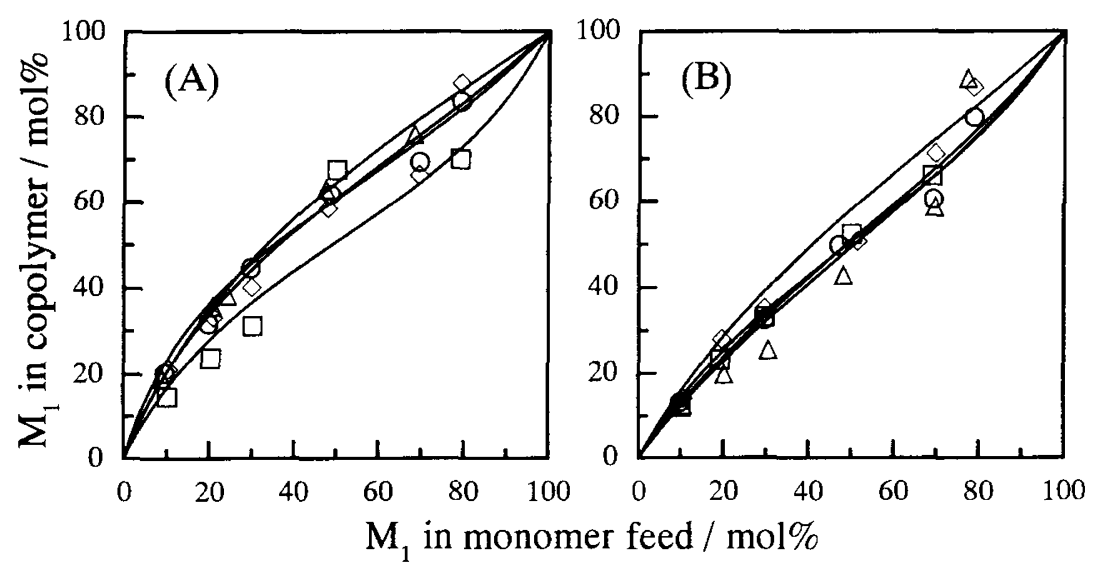

Figure 5. Copolymer composition curves for (A) RMOC-ST and (B) RMOC-MMA systems; RMOC $=(\bigcirc)$ MBMOC, $(\square)$ MPMOC, $(\triangle)$ PhEMOC, and $(\diamond)$ PhPMOC.
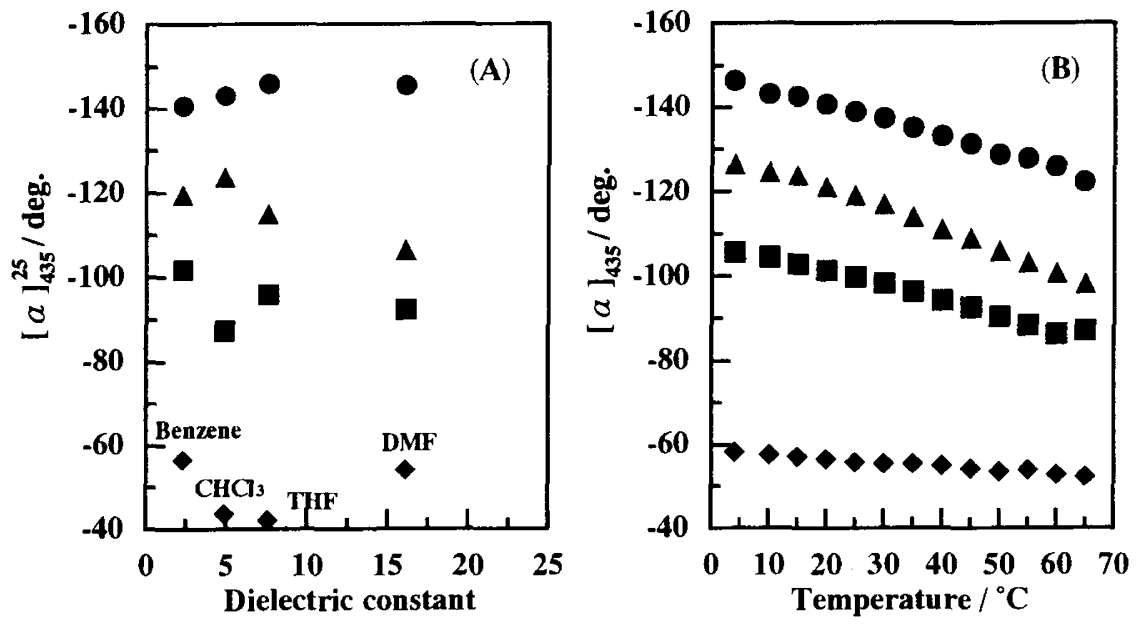

Figure 6. Relationships between specific optical rotations and (A) dielectric constants of solvents, and (B) measurement temperature in

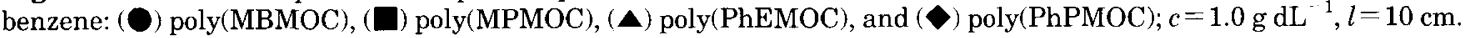

Table V. Radical copolymerizations of RMOC $\left(\mathrm{M}_{1}\right)$ with MOTSi $\left(\mathrm{M}_{2}\right)$ in THF $(3 \mathrm{~mL})$ at $60^{\circ} \mathrm{C}$ for $24 \mathrm{~h}^{\mathrm{a}}$ and preparation of columuns for HPLC

\begin{tabular}{|c|c|c|c|c|c|c|c|c|c|c|c|}
\hline \multirow{4}{*}{ Run } & \multirow{4}{*}{ Product } & \multirow{4}{*}{$\frac{\mathrm{RMOC}}{\mathrm{M}_{1}}$} & \multirow{4}{*}{$\frac{\begin{array}{c}\mathrm{M}_{1} \text { in } \\
\text { monomer }\end{array}}{\text { mol\% }}$} & \multirow{4}{*}{$\frac{\text { Yield }^{\text {b }}}{\%}$} & \multirow{4}{*}{$\begin{array}{c}\begin{array}{c}\mathrm{M}_{1} \text { in } \\
\text { copolymer }\end{array} \\
\text { mol\% }\end{array}$} & \multirow{4}{*}{$\frac{\bar{M}_{\mathrm{n}}^{\mathrm{d}}}{\times 10^{-4}}$} & \multirow{4}{*}{$\bar{M}_{\mathrm{w}} / \bar{M}_{\mathrm{n}}^{\mathrm{d}}$} & \multirow{4}{*}{$\frac{[\alpha]_{435}^{25}{ }^{e}}{\operatorname{deg}}$} & \multicolumn{3}{|c|}{ Column $^{\mathrm{f}}$} \\
\hline & & & & & & & & & \multirow[t]{3}{*}{ Type of CSP } & Content of poly & \multirow{3}{*}{ Plate number ${ }^{h}$} \\
\hline & & & & & & & & & & (RMOC)segment $^{\mathrm{g}}$ & \\
\hline & & & & & & & & & & $\mathrm{wt} \%$ & \\
\hline 1 & MB 50 & \multirow{2}{*}{ MBMOC } & 50.3 & 67.4 & 42.9 & 2.50 & 2.37 & -95.5 & & 21 & 175 \\
\hline 2 & MB $100^{i}$ & & 100 & 66.5 & 100 & 0.38 & 1.43 & ND & type II & 30 & 494 \\
\hline 3 & MP 50 & \multirow[t]{2}{*}{ MPMOC } & 49.3 & 49.2 & ND & 1.52 & 3.47 & $-62.1^{j}$ & type I & 24 & 483 \\
\hline 4 & MP $100^{i}$ & & 100 & 62.4 & 100 & ND & $\mathrm{ND}$ & ND & type II & 12 & 239 \\
\hline 5 & PhE 50 & \multirow[t]{2}{*}{ PhEMOC } & 49.3 & 78.6 & 42.7 & \multirow{2}{*}{$\mathrm{ND}^{2.36}$} & \multirow{2}{*}{$\begin{array}{l}2.47 \\
\mathrm{ND}\end{array}$} & \multirow{2}{*}{$\begin{array}{c}-69.6 \\
\text { ND }\end{array}$} & \multirow{2}{*}{$\begin{array}{l}\text { type I } \\
\text { type II }\end{array}$} & 31 & \multirow{2}{*}{$\begin{array}{l}191 \\
264\end{array}$} \\
\hline 6 & $\mathrm{PhE} 100^{\mathrm{i}}$ & & 100 & 72.1 & 100 & & & & & 31 & \\
\hline 7 & PhP 50 & \multirow{2}{*}{ PhPMOC } & 49.4 & 75.6 & ND & 1.42 & 3.03 & $-32.3^{j}$ & type I & 25 & 342 \\
\hline 8 & $\operatorname{PhP} 100^{\mathrm{i}}$ & & 100 & 69.8 & 100 & 0.18 & 1.91 & ND & type II & 34 & 327 \\
\hline
\end{tabular}

ND, Not determined. ${ }^{a}$ Initiator, 2,2'-azobisisobutyronitrile (AIBN) $=0.03 \mathrm{~mol} \mathrm{~L}^{-1}$; MOTSi, methacryloyloxypropyl trimethoxysilane; Run 1-3, 5, and 7-8: $\mathrm{M}_{1}+\mathrm{M}_{2}=0.8 \mathrm{~g}$; Run 4: $\mathrm{M}_{1}+\mathrm{M}_{2}=2.0 \mathrm{~g}$, Run 6: $\mathrm{M}_{1}+\mathrm{M}_{2}=1.8 \mathrm{~g}$. ${ }^{\mathrm{b}} \mathrm{MeOH}$-insoluble part. ${ }^{\mathrm{c}} \mathrm{By}{ }^{\prime} \mathrm{H}$ NMR. ${ }^{\mathrm{d}} \mathrm{By} \mathrm{GPC}$ with polystyrene standard. ${ }^{\mathrm{e}} c=1.0 \mathrm{~g} \mathrm{dL}{ }^{1}, l=10 \mathrm{~cm}$, THF. ${ }^{\mathrm{f}}$ Column, $150 \times 2 \mathrm{~mm}$, in methanol. ${ }^{\mathrm{g}} \mathrm{By} \mathrm{IR}^{\mathrm{h}}$ For toluene using methanol as eluent at flow rate $0.5 \mathrm{~mL} \mathrm{~min}{ }^{-1}$ at ambient temperature. ${ }^{i}$ Chain transfer agent, 3-mercaptopropyl trimethoxysilane $=0.06$ mol $\mathrm{L}^{-1}$. ${ }^{\mathrm{j}} c=1.0 \mathrm{~g} \mathrm{dL}^{-1}, l=5 \mathrm{~cm}$, THF. 


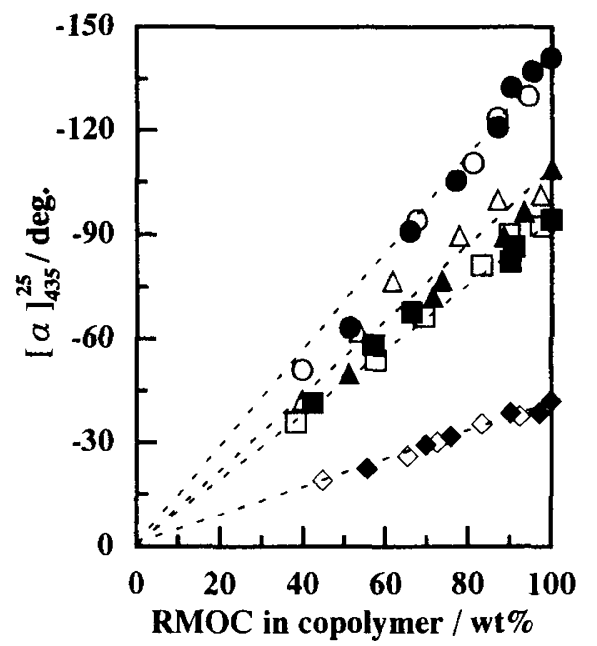

Figure 7. Relationships between specific optical rotations $[\alpha]_{435}^{25}$ and contents (wt\%) of the monomeric unit of RMOC in copolymer; (O) poly(MBMOC-co-ST)s, (O) poly(MBMOC-co-MMA)s, ( $)$ poly(MPMOC-co-ST)s, ( $\square$ ) poly(MPMOC-co-ST)s, (A) poly(PhEMOCco-ST)s, $(\triangle)$ poly(PhEMOC-co-MMA)s, $(\Delta)$ poly(PhPMOC-co-ST) and $(\diamond)$ poly(PhPMOC-co-MMA)s.

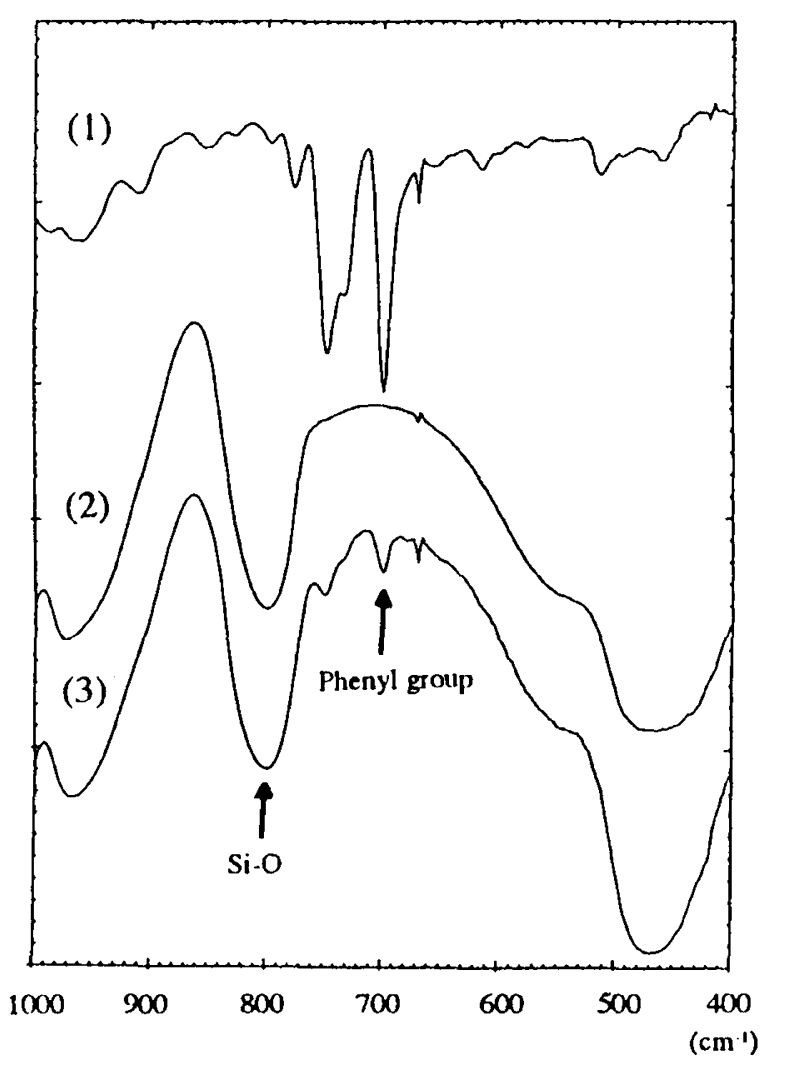

Figure 8. Infrared spectra for (1) poly(MBMOC), (2) silica gel, and (3) poly(MBMOC-co-MOTSi)-bonded silica gel.

tions of copolymers decreased with decreasing RMOC content, and the plots were extrapolated to $0^{\circ}$. The dotted lines refer to the relationship between specific optical rotation and content (wt\%) of the RMOC unit in a mixture of a poly(RMOC) and poly(ST) or poly(MMA). Accordingly, the chiroptical properties of the copolymers

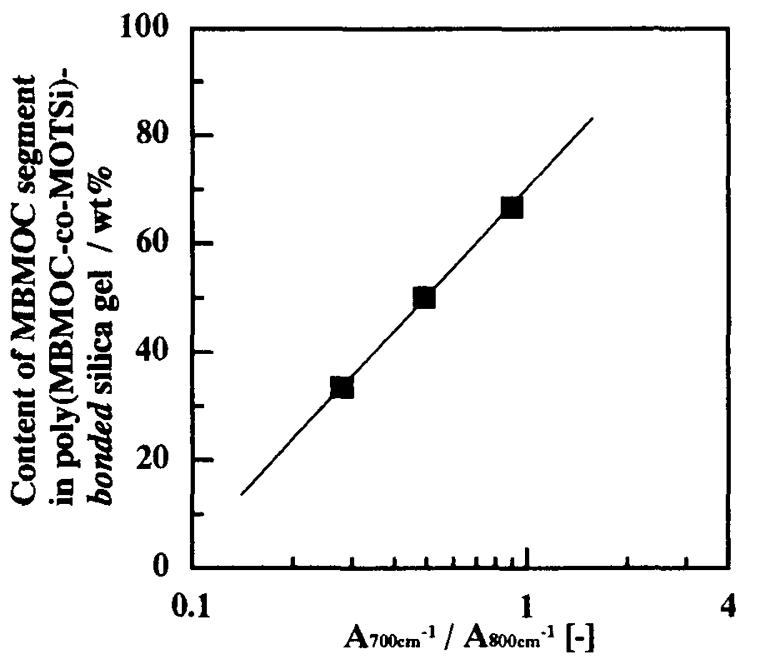

Figure 9. Calibration curve for content (wt\%) of MBMOC segment in poly(MBMOC-co-MOTSi)-bonded silica gel.

seem scarcely influenced by co-units of ST or MMA.

Preparation of CSPs and Chiral Recognition Ability of $\operatorname{poly}(R M O C) s$

To investigate chiral recognition ability of poly(RMOC), two of CSPs, poly(RMOC)-bonded silica gel (CSP-R100) and poly(RMOC-co-MOTSi)-bonded silica gel (CSP-R50), were prepared by the synthetic routs shown in Scheme 2. The reaction conditions and results are summarized in Table V. Figure 8 depicts IR spectra of poly(MBMOC), silica gel and poly(MBMOC-coMOTSi)-bonded silica gel. For poly(MBMOC-co-MOTSi)bonded silica gel, absorption due to phenyl groups appeared clearly at $700 \mathrm{~cm}^{-1}$. RMOC segment content on CSPs was found with calibration curves, as shown in Figure 9, that were obtained from the ratios $\left(A_{700 \mathrm{~cm}}{ }^{1} /\right.$ $A_{\left.800 \mathrm{~cm}^{-1}\right)}$ of absorbance at $700 \mathrm{~cm}^{-1}$ and $800 \mathrm{~cm}^{-1}$ in IR spectra of suitable mixture of silica gel and chiral polymers.

The ability of CSPs prepared with RMOC for chiral recognition of racemates $\mathbf{1}-\mathbf{1 2}$ (Scheme 3) was examined using HPLC. CSPs did not resolve all racemates in the normal phase such as 2-propanol/n-hexane, but resolved racemates $\mathbf{1}-\mathbf{5}$ in the reversed phase such as methanol/ $\mathrm{H}_{2} \mathrm{O}$. Table VI shows the results of HPLC analysis using methanol/ $/ \mathrm{H}_{2} \mathrm{O}$ as the mobile phase. Typical HPLC chromatograms of racemic manderic acid ethyl ester $(1)$ in methanol/water $=7 / 3$ with $\mathrm{CSP}-\mathrm{PhP} 100$ are shown in Figure 10. Difference in chiral discriminating ability between CSPs of types I and II were observed. For example, ketoprofen (4) was not resolved on CSPMP 50, but on CSP-MP 100. Thus, the chiral discriminating ability of poly(RMOC) may be due to the secondary and/or higher-ordered structure of the polymer. For racemate 1, separation factors for CSP-MP100 (or 50) and CSP-PhP (or 50) were larger than those for CSP-MB 100 (or 50) and CSP-PhE100 (or 50). Thus, the methylene group at the $\beta$-position in the amino acid residue of the RMOCs may play an important role in chiral discrimination. 


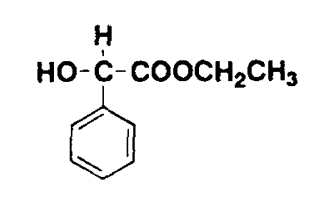

1: Mandelic acid ethyl ester<smiles>NC(CC(=O)O)C(=O)O</smiles>

5: Aspartic acid<smiles>CC(O)c1cccc2ccccc12</smiles>

2: Methyl-1-naphthyl alcohol<smiles>O=C(O)c1ccccc1</smiles>

2: Mandelic acid<smiles>N[C@H](Cc1ccccc1)C(=O)O</smiles>

6: Phenyl alanine<smiles>CC(O)c1ccc2ccccc2c1</smiles>

10: Methyl-2-naphthyl alcohol<smiles>CC(C(=O)O)c1cccc(C(=O)c2ccccc2)c1</smiles>

3: Ketoprofen<smiles>N[C@H](C(=O)O)c1ccccc1</smiles>

7: Phenyl glycine

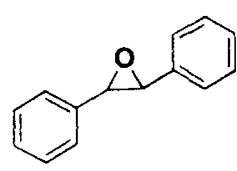

11: trans-Stilbene oxide<smiles>N[C@@H](Cc1cnc[nH]1)C(=O)O</smiles>

4: Histidine<smiles>OC1CCCc2ccccc21</smiles>

8: 1, 2, 3, 4-Tetrahydro1-naphthyl alcohol

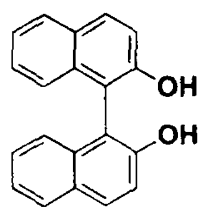

12: 1, 1'-Bi-2-naphthyl alcohol

Scheme 3.

Table VI. Chromatographic resolutioin of recemates $1-12$ on the CSP-R 100 (type I) and CSP-R 50 (type II) ${ }^{2}$

\begin{tabular}{|c|c|c|c|c|c|c|c|c|c|c|c|c|c|c|c|c|}
\hline \multirow{3}{*}{ Racemate } & \multicolumn{8}{|c|}{ CSP-R 100 (type I) } & \multicolumn{8}{|c|}{ CSP-R 50 (type II) } \\
\hline & \multicolumn{2}{|c|}{ MB 100} & \multicolumn{2}{|c|}{ MP 100} & \multicolumn{2}{|c|}{ PhE 100} & \multicolumn{2}{|c|}{ PhP 100} & \multicolumn{2}{|c|}{ MB 50} & \multicolumn{2}{|c|}{ MP 50} & \multicolumn{2}{|c|}{ PhE 50} & \multicolumn{2}{|c|}{$\mathrm{PhP} 50$} \\
\hline & $t_{1}{ }^{\mathrm{b}}$ & $\overline{\alpha^{\mathrm{c}}}$ & $t_{1}$ & $\alpha$ & $t_{1}$ & $\alpha$ & $t_{1}$ & $\alpha$ & $t_{1}$ & $\alpha$ & $t_{1}$ & $\alpha$ & $t_{1}$ & $\alpha$ & $t_{1}$ & $\alpha$ \\
\hline $\mathbf{I}$ & 2.30 & 1.16 & 2.10 & 1.33 & 2.30 & 1.10 & 2.31 & 1.28 & 2.28 & 1.14 & 2.36 & 1.31 & 2.16 & 1.21 & 2.35 & 1.29 \\
\hline 2 & $2.46^{\mathrm{d}}$ & 1.21 & 3.38 & 1.23 & $1.78^{\mathrm{e}}$ & 1.68 & $3.60^{\mathrm{d}}$ & 1.29 & 3.08 & 1.0 & $3.04^{\mathrm{d}}$ & 1.37 & $1.60^{\mathrm{f}}$ & 1.0 & 1.76 & 1.34 \\
\hline 3 & 5.00 & 1.0 & 4.62 & 1.18 & 1.92 & 1.0 & 7.72 & 1.0 & ND & & 7.72 & 1.0 & $1.56^{\mathrm{f}}$ & 1.0 & 2.28 & 1.0 \\
\hline 4 & 3.50 & 1.0 & 3.92 & 1.0 & 1.48 & 1.0 & 4.00 & 1.0 & 3.34 & 1.0 & 1.96 & 1.34 & 3.58 & 1.0 & 2.04 & 1.27 \\
\hline 5 & $2.24^{\mathrm{d}}$ & 1.47 & 5.00 & 1.0 & 2.04 & 1.0 & ND & & 2.56 & 1.0 & 2.10 & 1.0 & $1.84^{\mathrm{g}}$ & 1.18 & ND & \\
\hline 6 & 2.24 & 1.0 & 2.10 & 1.0 & 2.40 & 1.0 & 2.10 & 1.0 & 2.04 & 1.0 & 1.96 & 1.0 & 2.04 & 1.0 & 1.94 & 1.0 \\
\hline 7 & 2.20 & 1.0 & 2.08 & 1.0 & 2.30 & 1.0 & 2.04 & 1.0 & 2.10 & 1.0 & 1.84 & 1.0 & 1.90 & 1.0 & 1.84 & 1.0 \\
\hline 8 & 2.40 & 1.0 & 2.16 & 1.0 & 2.44 & 1.0 & 2.26 & 1.0 & 2.32 & 1.0 & ND & & 2.40 & 1.0 & 2.54 & 1.0 \\
\hline $\mathbf{9}$ & 3.46 & 1.0 & 3.84 & 1.0 & 3.20 & 1.0 & 4.12 & 1.0 & 3.28 & 1.0 & 4.74 & 1.0 & 3.62 & 1.0 & 3.86 & 1.0 \\
\hline 10 & 2.56 & 1.0 & 2.26 & 1.0 & 2.56 & 1.0 & 2.74 & 1.0 & 2.52 & 1.0 & 2.90 & 1.0 & 2.50 & 1.0 & 2.84 & 1.0 \\
\hline 11 & 5.36 & 1.0 & 3.56 & 1.0 & 4.60 & 1.0 & 7.40 & 1.0 & 4.80 & 1.0 & 8.56 & 1.0 & 6.16 & 1.0 & 6.02 & 1.0 \\
\hline 12 & 4.72 & 1.0 & 3.06 & 1.0 & 4.90 & 1.0 & 5.10 & 1.0 & 3.50 & 1.0 & 5.50 & 1.0 & 3.40 & 1.0 & 4.80 & 1.0 \\
\hline
\end{tabular}

ND, Not determined. ${ }^{a}$ Eluent: $\mathrm{MeOH} / \mathrm{H}_{2} \mathrm{O}=7 / 3$, flow rate $=0.2 \mathrm{~mL} \mathrm{~min}{ }^{-1} .{ }^{\mathrm{b}}$ Retention time of the first-eluted enantiomer (min).

${ }^{\mathrm{c}}$ Separation factor $=t_{2}$ (retention time of the second-eluted enantiomer $\left.(\min )\right) / t_{1}$. ${ }^{\mathrm{d}}$ Eluent: $\mathrm{MeOH} / \mathrm{H}_{2} \mathrm{O}=7 / 3 . \quad{ }^{\mathrm{e}} \mathrm{Eluent}: \mathrm{MeOH} / \mathrm{H}_{2} \mathrm{O}=0 / 10$.

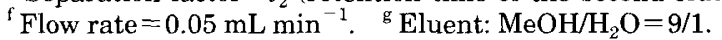

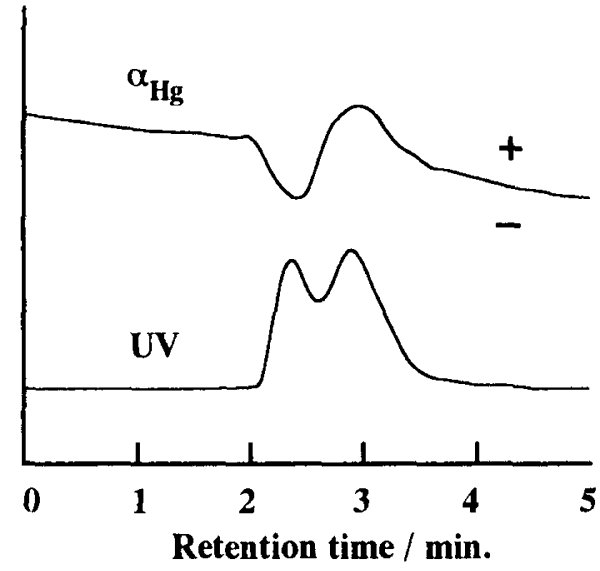

Figure 10. HPLC chromatograms of racemic manderic acid ethyl ester (1) in a $\mathrm{MeOH} / \mathrm{H}_{2} \mathrm{O}(7 / 3)$ mobile phase; packing material, poly(PhPMOC)-bonded silica gel (type I); column, $150 \mathrm{~mm} \times 2 \mathrm{~mm}$; flow $=0.2 \mathrm{~mL} \mathrm{~min}^{-1}$. Top and bottom curves were monitored by a $\mathrm{UV}(254 \mathrm{~nm})$ and polarimetric detector, respectively.

\section{CONCLUSION}

Four new chiral methacrylates, MBMOC, MPMOC, PhEMOC, and PhPMOC, were synthesized from $\alpha$ amino acids and MOI. Radical homopolymerizations of RMOC's were carried out in various solvents to obtain the corresponding polymers having hydrogen bonds due to urethane moieties. Chiroptical properties of poly(RMOC)s were slightly influenced by dissolving solvents and temperature. Monomer reactivity ratios, $Q$, and $e$ of RMOC were determined. Chiroptical properties of the copolymers were scarcely affected by co-units of ST and MMA. CSPs chemically prepared from RMOC's and silica gel proved for the resolution of racemic compounds 1-5 by HPLC. 


\section{REFERENCES}

1. S. Matsuhiro, Konbatekku, 5, 8 (1997).

2. a) H. Kamogawa, H. Kohno, and R. Kitagawa, J. Polym. Sci., Part A: Polym. Chem., 27, 487 (1989); b) C. Decker and K. Moussa, Eur. Polym. J., 27, 881 (1991); c) I. Francis, S. Arjen C. Israel, and S. Johannes, J. Polym. Sci., Part A: Polym. Chem., 31, 239 (1993).

3. a) H. Albrecht and W. Wunderlich, Angew. Makromol. Chem., 145/146, 89 (1986); b) S. Savaskan and B. Hazer, Angew. Makromol. Chem., 239, 13 (1996); c) N. Monzner, U. K. Fischer, T. Volkel, and V. Rheinberger, Angew. Makromol. Chem., 245, 155 (1997).

4. C. H. Bamford, K. G. Al-Lamee, I. P. Middleton, J. Paprotny, and R. Carr, Bull. Soc. Chim. Belg., 99, 919 (1990).

5. Y. K. Lee, K. Onimura, H. Tsutsumi, and T. Oishi, J. Polym. Sci., Part A: Polym. Chem., 38, 4315 (2000).

6. S. G. Allenmark, "Chromatographic Enantioseparation", Ellis Howood Ltd., Chichester (1988).
7. For example, Y. Okamoto, Chemtech, 1987, 176.

8. Y. Tamai, P. Qian, K. Matsunaga, and S. Miyano, Bull. Chem. Soc. Jpn., 65, 817 (1992).

9. a) G. Blaschke, Angew. Chem., Int. Ed., Engl., 19, 13 (1980); b) G. Blaschke, W. Broker, and E. Frankel, Angew. Chem., Int. Ed., Engl., 25, 830 (1986).

10. D. Arlt, B. Bomer, R. Grosser, and W. Lange, Angew. Chem., Int. Ed., Engl., 30, 1662 (1991).

11. T. Otsu and M. Kinoshita, "Koubunshigousei Jikkenhou" Kagakudoujin, Kyoto, Japan, 1972, pp 69-91.

12. A. Abiko and S. Masamune, Tetrahedron Lett., 38, 5517 (1992).

13. P. O'Brien, H. R. Powell, P. R. Raithby, and S. Warren, $J$. Chem. Soc., Perkin Trans., 1, 1031 (1997).

14. F. Tüdös, T. Kelen, T. Foldes-Berezsnich, and B. Turcsanyi, J. Macromol. Sci., Chem., A10, 1513 (1976). The monomer reactivity rations were determined by the method 6 described in this paper.

15. T. Jr. Alfrey and C. C. Price, J. Polym. Sci., 2, 101 (1947). 